that period I had drawn attention to what I pointed out as the two principal earthquake great circles-one, the Japan and Rocky Mountain system, with one of its poles in $170^{\circ} \mathrm{W}$. long., $25^{\circ} \mathrm{S}$. lat. ; the other, the Himalayic, with its north pole approximately in $45^{\circ} \mathrm{N}$. lat., $160^{\circ} \mathrm{W}$.long. The former has been frequently described, and Scrope ("Volcanoe=," p. 303) suggested a theory to explain it occurrence. The latter is little less remarkable, and is at the moment even more interesting, as, with the exception of the Carolina earthquake, all the great earthquakes and volcanic eruptions of the last five years may be referred to it. I may instance the cases of Krakatão, Kashmir, the Caucasus, Spain, Cotopaxi, New Zealand, and the recent Mediterranean disturbance, all of which oscurred within a few degrees of the line or actually on it. Nuw it is remarkable that this line is marked through a considerable portion of its course by the presence of disturbed Miocene rocks, so much so that I have felt justified in calling it the Miocene line.

The paper referred to contained a theory too long to be worked out in the compass of a let er, but founded on the changes in form which must occur when a plastic body falls by the action of gravity towards a primary. A little consideration will show that, as the action of gravity is inversely proportionate to the square of the distance, the forward portion of such a body will be continually pulled away from the posterior, and an original sphere will in its descent become deformed into a prolate spheroid. Now the result is, I believe, calculable for a body like the earth, even under the present conditions of its annual approach to the sun, in other words its fall from aphelion to perihelion. During periods of extreme eccentricity of the orbit the fall and consequent deformation were much greater. The main factors in the calculation are of course: (I) the distance from the primary of the commencement of the fall; $(2)$ the diameter of the falling body; (3) the distance fallen; and (4) the comparative masses of the primary and the attracted body. Beyond this, consideration has to be given to what we may term the specific resistance to deformation of the particular body. The latter, indeed, seems to be the principal factcr in determining the amplitude and periodicity of earthquakes.

It is difficult for the geologist at this remote spot in the Far East to keep in touch with the daily progress of geology at home, but there is one probably counterbalancing advantage-in the enlarged view he has to take of the mid-Tertiary epoch as a factor in geologic change.

Shanghai, November 30,1886

\section{THE CALENDAR AND GENERAL DIRECTOR Y OF THE SCIENCE AND ART DEPARTMENT}

' 'HERE is a general impression on the Continent, and even in England, that English teachers of science carry on their work with little direct relation to one another. Twenty-five years ago this impression was not incorrect, but any one who will take the trouble to read the "Calendar and General Directory of the Science and Art Department for the year i 887 ," lately published, will see that it is no longer true, and that very important steps have been taken towards the establishment of an organised and efficient system of scientific instruction. At South Kensington we have now a School of Science, which maintains the most intimate connection with a vast number of science schools and classes in all parts of the United Kingdom. Here we have at least the germs of a proper system, and it depends upon the country itself whether we are to remain content with what has been achieved, or are to continue the work we have begun until it can be pronounced completely adequate to the needs of modern times.

The movement which has led to these results may be said to have begun in 1853, when the Department of Practical Art was expanded into the Department of Science and Art. The immediate object of this change was to secure that the advancement of practical science should be directly encouraged, and it was decided that the end could be most surely attained by "the creation in the metropolis of a school of the highest class, capable of affording the best instruction and the most perfect train. ing," and by help rendered to local institutions for scientific education. For some time it seemed not improbable that the scheme would be, at least in part, a failure. No general system of making grants applicable to the whole country was devised until i 859. Experimental schools were established by special Minutes, the arrangement usually being that the teachers were to receive payments from the Department in the nature of certificate allowances, and that their incomes, from fees, subscriptions, and other sources, were to be guaranteed by the Department for a certain number of years at amounts varying in different places. In this way science schools were opened at Aberdeen, Birmingham, Bristol, Barking, Leeds, Newcastle-on-Tyne, Poplar, Stoke-on-Trent, St. Thomas's Charterhouse, Truro, Wigan, and Wandsworth. It was found, however, that there were but few places where a man could earn his living by teaching science alone ; and in I859 the only science classes in operation under the Department, irrespective of the Navigation Schools, were those at Aberdeen, Birmingham, Bristol, and Wigan, the number of persons in attendance being 395 . Then a new plan was tried. In I859, when the late Lord Salisbury was Lord President, the first General Science Minute was passed, enabling any place to establish science classes, and to obtain State aid according to certain fixed rules. The effect of this measure surpassed the hopes of those by whom it had been suggested. A number of new schools and classes were rapidly formed, so that, in May $\mathbf{I} 86 \mathbf{I}$, at the first general and simultaneous examination of classes, there were 38 classes with 1330 pupils, not including some 800 pupils in classes not under certificated teachers. Since that time there has been constant progress, as the following table will show :-

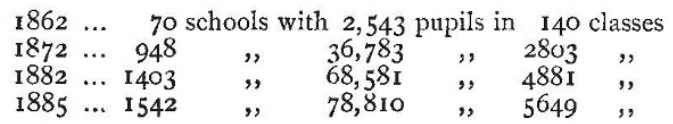

In some schools there are classes both for science and for art, and in such cases it is interesting to note the relative proportion of the number of pupils in the two departments. At the School of Science and Art in Reading, for instance, there are 200 art students, and only 90 students of science. At the Central Board School, Rochdale, on the other hand, while there are only 50 students of art, there are I9o science students. In some instances the numbers are evenly, or almost evenly, balanced. At a school in Deptford there are in each department 160 students, and at another, in Bristol, art has 360 students, science 350 .

The number of teachers varies, of course, very considerably. The following tables, compiled from the details presented in the "Calendar and General Directory," show the number of schools which have each three or more teachers :-

I.

Schools in which both Science ant Art Classes are held

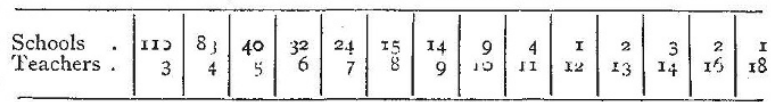
II.

Schools in which Science Classes only are held

\begin{tabular}{lr|r|r|r|r|r|r|r|r|r|r|r}
\hline Schools : & I05 & 36 & 24 & rx & I & 2 & 4 & 2 & I & x & I \\
Teachers $:$ & 3 & 4 & 5 & 6 & 7 & 8 & 9 & I0 & II & I3 & I4 \\
\hline
\end{tabular}

The progress of the central institution-the "school of the highest class, capable of affording the best instruction"-has been in its own way not less remarkable. The removal of some of the courses of the School of Mines to South Kensington greatly increased the 
number of students, partly because the instruction was rendered more thorough and efficient by the addition of laboratory and practical instruction in physics, mechanics, biology, and geology, and partly because South Kensington was more convenient for students than Jermyn Street or Oxford Street. The school was also rendered more useful by the fact that, after the transfer, a few teachers, and promising students who undertook to become teachers, were brought up to London to be trained. This system has been developed, and now from fifty to sixty teachers are annually trained in different branches of science. A system of short summer courses for teachers has also been organised, and this opportunity of improving themselves is highly valued by the teachers, about I 80 or 200 of whom are selected annually from some 500 or 600 applicants.

The affiliation of the School of Mines to the Normal School of Science in 1881 marked an era in the history of the institution and in the history of scientific work and education in this country. Students of all classes receive in these united schools systematic instruction in the various branches of physical science. The institution is primarily intended for the instruction of teachers and of students of the industrial classes selected by competition in the examinations of the Science and Art Department, but other students are admitted so far as there may be accommodation for them, on the payment of fees fixed at a scale sufficiently high to prevent undue competition with institutions which do not receive State aid.

All this is fully and clearly set forth in the "Calendar and General Directory," where also the reader will find ample details as to the Science Collections, the aid granted to local museums, the Committee on Solar Physics, the relation of the Government to scientific research, the Geological Survey, the Museum of Practical Geology, the Mining Record Office, and the scientific establishments of Edinburgh and Dublin.

In an article on "National Education in Science and Art," the Times on Monday last expressed a doubt whether, after all, any country can be much ahead of England in the number and excellence of its scientific institutions. The Times takes far too favourable a view of the relative position of the United Kingdom in such matters. Recent Consular reports have shown that our traders are being steadily beaten by German competitors in many great foreign markets; and the explanation is that, notwithstanding the progress we have made, our system of scientific instruction will not compare, in comprehensiveness and thoroughness, with that which has grown up in Germany. The Times, although unwilling to admit the superiority of our rivals, readily grants that as a nation we do not yet do enough for the promotion of science. It says :--

"When the general condition of popular artistic and scientific instruction is viewed, there can be no question that it is not in accordance with national responsibilities, whatever the average may be elsewhere. A primary result of the discovery is to abate some of the admiring content which study of the contents of the Science and Art Department's 'Calendar and Directory' is calculated to produce. To the Science and Art Department has been committed the task of imbuing the nation with those two extensive branches of human learning. The depreciatory estimates so freely offered in these days of the industrial attainments of the nation in each of them suggest either that the Department is not altogether equal to the enterprise, or that it has not been provided with the proper instruments."

The Times urges, with much force, that wealthy men have a magnificent opportunity of serving their country by following the example of the late Sir Joseph Whitworth in the endowment of scholarships, exhibitions, and prizes for students of science. With its remarks on this point all who are interested in science will agree; but it is necessary to point out that, however generous private persons may be, they cannot possibly meet the wants of England, with regard to science, in our time. This task can be properly undertaken only by the community as a whole, acting through its organ, the State. If it is not undertaken on the scale which circumstances have rendered necessary, we must be prepared to pay the penalty in diminished commerce and industry. On the other hand, the success which has attended our efforts in the right direction in the past ought to encourage us to make further sacrifices. There cannot be the slightest doubt as to the eagerness with which increased opportunities for scientific education of the highest order would be taken advantage of. At South Kensington there is not nearly room enough for the large number of students who annually seek admission, and like pressure will probably soon be experienced at many less important centres of scientific training. Here the Times speaks out strongly and well :-

"If the industrial classes in England be more or less deficient in taste and technical intelligence, it is from absence, not of natural aptitude, but of educational opportunities. Keenness of Continental competition may be far from an unmixed evil if it frighten Englishmen who have the ability into using it for the remedy of the shortcoming. Dulness and mental lethargy are in themselves evils, apart from the danger they cause of a loss of trade. A workman without insight into the meaning of the work he is doing, and with no perception of its real capabilities, is a mere bondsman to his occupation, instead of its master. While we suspect, as we have intimated, the existence of an exaggerated tendency to extol foreign technical training, the British mechanic will have no reason to regret the propensity, if it conduce to his equipment with the means of industrial enlightenment needed to convert his vocation from base drudgery into an art."

That the working classes are becoming alive to the necessity of an improved system of scientific and technical instruction may be inferred from the resolution on the subject which Mr. Howell proposes to move in the House of Commons. This resolution we print elsewhere, and our readers will agree with us in wishing $\mathrm{Mr}$. Howell all success in the admirable enterprise he has undertaken.

\section{THE PROGRESS OF ASTRONOMICAL PHOTOGRAPHY}

IN the Annuaire for the present year, published by the Bureau des Longitudes, is an important article by Admiral Mouchez, the Director of the Paris Observatory. The article is really a history of the various applications of photography used by astronomers up to the present time, and the history is very well done. The article contains many details relative to the work which has recently been going on in the Paris Observatory, which we think will be read with very general interest.

In the new instruments which the Brothers Henry have recently constructed at the Observatory, before a plate is taken the telescope is pointed approximately to a bright star, which is examined with an ordinary eye-piece, armed with a blue glass. In this way a slide can be placed very near the chemical focus, but in order to determine the focus exactly, an image of a star is made to run six or seven times along a very small plate at different marked distances inside and outside the focal point, as previously determined. An inspection by a magnifying glass of the different trails left by the star on the cliché shows which was the most exact chemical focus employed to produce them. This when once done really needs no repetition, but as a matter of fact the operation is repeated once a month.

Another point which the Brothers Henry have already settled is, that in the case of very many photographic plates of extreme sensitiveness the plates are practically 